\title{
James Wenceslas Papez's journey into eugenics
}

\author{
Thomas D. Sabin ${ }^{1}$ (D)
}

Received: 25 July 2019 / Accepted: 31 August 2019 / Published online: 22 October 2019

(C) The Author(s) 2019

As our society faces a burgeoning new prospect for a "neoeugenics" based on our ability to alter our genome, it is timely to reflect on the involvement of a famous neuroscientist in the eugenics movement of the first half of the twentieth century.

James Papez was born in Minnesota and graduated from the University of Minnesota in 1911. Although he was an M.D., he established himself as a neuroanatomist with expertise in comparative anatomy. He became widely known for his anatomical publications and as an educator during his career at Cornell Medical School from 1920 to 1951. However, Papez's enduring eponymous fame is based on his insight that certain medial structures of the hemisphere formed a functionally important circuit which he identified with emotion but is now more strongly associated with memory. This concept was based on his intimate knowledge of the connectivity of the "ensemble of structures" of the medial wall of the cortex, early animal ablation experiments, and in part on his observation that rabies caused a variety of apparent emotional and behavioral changes in its late phase when the virus massively invaded limbic structures, especially the hippocampus. He actually performed injections of rabies virus into animals to discern the distribution of the organisms within the brain. These observations were published in his "A Proposed Mechanism of Emotion" [1]. In the summary, he stated that "It is proposed that the hypothalamus, the anterior thalamic nuclei, the gyrus cinguli, the hippocampus and their interconnections constitute a harmonious mechanism which may elaborate the functions of central emotion, as well as participate in emotional expression," Medical students have struggled to memorize these connections ever since.

Although Papez obtained his medical degree from the University of Minnesota, his career was primarily as an

Thomas D. Sabin

tsabin@tuftsmedicalcenter.org

1 Tufts University School of Medicine, Boston, MA, USA anatomist. He published broadly in the field including such esoteric topics as the subdivisions of the facial nucleus, the turtle thalamus, and the evolution of the medial geniculate nucleus [2-4]. He had no special experience in the study of human behavior and maintained only minimum involvement in clinical practice, so it is remarkable that he applied his anatomical insights into human emotions. Although Broca first described the limbic lobe (le grand lobe limbique) in 1878, this work was not cited by Papez [5]. After Papez's observations, it was Paul MacLean who introduced the term limbic system and added parts of the frontal lobe, temporal cortices and especially the amygdala to capture the circuitry involved in human emotions [6]. During much of his career, Papez maintained a very heavy teaching load. What started out as a laboratory manual for a neuroscience course became a full-length book called Comparative Neurology: A Manuel and Text For the Study of the Nervous System and is still in print [7]. It is richly illustrated by his wife, Pearl Sowden Papez. The importance of gyral cortical folding in evolution of the brain is emphasized but no trace of Papez's later interest in eugenics is evident in this book.

Papez's role in the eugenics movement is not well known. He made an effort to relate the patterns of cortical gyration to the intelligence and talents of individuals. Neuropathologists and anatomists who deal with large numbers of human brains do develop a sense that there are singular features in the gross appearance of individual brains as distinctive as faces, and Papez too endorses that observation. He emphasized this point by publishing side by side photographs of the brains of a pauper and that of a normal young student [8]. He also showed the comparison of gyral complexity in a newborn infant and a normal adult to bolster the view that talent was reflected in the gross anatomy of the cerebral cortex (r).

Papez studied the detailed cortical anatomy of three accomplished individuals in order to illustrate the widely held belief that since evolution produced increase cognitive abilities in association with increasing cortical area by 
dramatically enhancing the cortical folding patterns, the difference in individuals would also be reflected in the richness of gyral folding [9-11]. These papers were published with the name of the patient as part of the title (preHIPAA) along with an accompanying biographical sketch. The brains used as controls were divided into three categories: (1) those of cultivated individuals of unusual achievement, (2) those of ordinary orderly folk with no remarkable accomplishment, and (3) those of a lower class with poor or negative life characteristics. Social sophistication and standing seem to count for Papez as much as intellectual horsepower. His studies focused on the cortex with a minimal comment on subcortical gray or features of the brainstem. Papez's interest in this approach was a continuation of his predecessor at Cornell, Burt G. Wilder M.D. (1841-1925) who founded and built the still extant brain collection at that institution and who also studied the brain anatomy of distinguished individuals. Papez published a study of Wilder's brain anatomy in 1929 [11]. This type of study has been very common and is usually focused on exceptional individuals. Russian neuroscientists published accounts of the brain anatomy of Lenin, Bekkhterev, Rossolimo, Kozhevnikov, and Korsakov [12]. Donaldson and Canavan studied the brains of G. Stanley Hall, Sir William Osler, and Edward Sylvester Morse [13]. This practice continues and a publication in 2013 analyzing Albert Einstein's brain appeared [14]. This report is based on the analysis of photographs of the whole brain. Shortly after Einstein's death, these pictures were obtained and then brain was divided into 240 blocks intended for histological study. Once again, frontal and temporoparietal association areas showed complex gyral patterns. Modern efforts using high-resolution MRI and neuropsychological testing in 440 healthy adults and 662 normal children support the notion that the degree of cortical folding or gyrification did correlate with general intelligence. Specific areas some also noted by Papez showed the strongest correlations. These included the prefrontal cortex, inferior parietal lobule, the temporoparietal area, cingulate, fusiform, and insular cortex [15].

Papez's most detailed study is on The Brain of Helen H. Gardener (Alice Chenoweth Day) and begins with an account on numerous accomplishments during her life [10]. She was a tireless and effective worker in behalf of women's suffrage, had leadership roles in education for women, and was the author of seven books. She herself became interested in brain anatomy, and her book "Sex in Brain" is a rebuttal of the statement made by a doctor that the female brain was inferior in nineteen ways! Her biographical sketch concludes with a family tree containing several titled Englishmen back to the sixteenth century. She willed her brain for study to Prof. Burt Wilder. Her formalinized brain was compared with 40 female and 40 male half-brains from the Cornell collection (Fig. 3).

Papez's examination techniques were simple, relying on a tape measure for gyral width and sulcal depth and planimeter to obtain a myriad of measurements focused on the cortical gyration and size of the corpus callosum. The state of the subcortical gray nuclei and brainstem was not detailed. The observations were grouped for discussion in six areas: the central, frontal, precuneal, parietal, temporal, and occipital. Brains from the Wilder collection that were used as controls were classified into three broad categories which included those from "cultivated individuals of unusual achievement, those of ordinary orderly individuals with no special achievements and those of the lower class with a negative record of achievement or bad record" [8].

In the case of Helen H. Gardener, Papez summarized "Brain-pattern features" correlated with achievement in this and other brains of both sexes are the large size and development of (1) the orbitomarginal area around the sulcus radiatus in the brow region; (2) the superior occipital and occipitoparietal areas in the occipital region around the visual area, and (3) the inferior parietal area [10]. "In this and other female brains the frontal regions and precuneus are relatively smaller than in males. The chief sex difference is in the smaller size of the female precuneus" [4].

Although the three papers reporting individual brains were filled detailed measurements, the summary and conclusions were quite brief and conservative. For example, his comment on the Sutherland brain stated: "The main features of this brain are its generally large size, a wealth of convolutional development in the parietal, occipital and temporal regions." The outstanding feature was the exceptionally large size of the precuneus [9]. (Current functional imaging indicates this is a major way-station on the default network.) The frontal region was of average size, but the inferior frontal convolution in its anterior part was strongly developed in males.

These three papers reporting the brain anatomy of these accomplished individuals were published in standard professional journals but lest there be any doubt about his eugenic motives there is paper in Eugenics, the official organ of the American Eugenics Society. This paper was entitled the Human Brain and appeared in eight parts designed to introduce the readership to an overview of brain structure particularly as it applies to eugenics [8]. Some of his most revealing comments include:

"To the eugenicist many other questions will naturally occur, particularly in relation to the hereditary and cultural capacity of the brain and its potentialities for the betterment of the human species." 
"The Cornell Brain Collection includes the brains of men and women of all degrees of mentality: and it has been possible to make some comparisons of brains of the different classes. At the opposite ends of the collection there appear to be two kinds of brains, one, a poorly developed type with simply formed convolutions and the other a well-developed type with complexly formed convolutions."

"The advanced type of brain is more richly convoluted. Such a brain has a more complicated pattern with narrow complexly formed convolutions and a greater number of secondary gyri and sulci. Such brains are usually found to belong to individulals from the cultured or scholastic classes."

Racial comments do enter the discussion [8]. "That the simply convoluted brains represent a lower stage of evolution or a primitive type and that the complex brains represent a more highly developed or advanced type of brain is a view expressed by some investigators. This explanation appears in accord with what is known of the brains of primitive men, such as the Neanderthal race, which appears to have much coarser convolutions. Their association areas, and in particular, the frontal lobes, were much inferior in size and complexity of convolutions to those of modern man. To a lesser degree this is true for the brains of the Papuan, the Egyptian Fellah, the Negro and some other backward peoples of modern times. If this explanation is a correct one it is of great importance to the eugenicist, because it shows that behind the process of growth there is also a genetic factor which determines certain tendencies of growth and sets limits in its expression."

"Hence it may happen that in small but more complexly organized brains such as those of James E. Oliver, Anatole France, and Burt G. Wilder. Their performance was of high order because of superior structural and functional organization rather than because of large size. But it must be remembered the in many cases the greater size in addition to this superior functional and structural organization has been a factor of enormous value in the production of creative genius."

Every generation inevitably turns to the latest technology to try to understand brain function and although correlations with intelligence may be observed no deep understanding of intelligence, talent, or creativity has emerged.

The opprobrium which is now attached to eugenics as a result of Hitler's grotesque and calamitous perverted use of this notion may color our opinion of Papez. The revelation of his involvement in eugenics must be judged in the light of the fact that eugenics was very popular in the USA during his time, even in the medical, legal, and scholarly communities.

Eugenics was founded by Charles Darwin's cousin in England 1883 and focused on enhancing positive trait. By the time the movement moved transatlantic and reached its peak in the 1920-1930s, the darker side of preventing negative traits became part of the agenda. Other conspicuous neurological figures were devotees of eugenicsFoster Kennedy and William Lennox backed sterilization and euthanasia for the severely disabled [16]. Children were judged at state fairs on whether they reflected successful breeding. Faculty at prestigious universities were zealous supporters of eugenics. The Supreme Court with Chief Justice Oliver Wendell Holmes presiding approved involuntary sterilization with an 8:1 vote in the 1927 now infamous Buck v. Bell case. Some 70,000 Americans were sterilized [17]. Two prominent presidents of Harvard were enthusiastic eugenicists. The wide appeal to the intellectual class was that it seemed to be an application of Darwin's work and thus a rapid way of speeding up evolutionary progress of Homo sapiens. Several prominent Harvard faculty members taught courses in eugenics, wrote important text books, and became public figures endorsing the principles. Adam Cohen writes "In part because of its overall prominence and influence on society, and in part because of its sheer enthusiasm, Harvard was more central to American eugenics than any other university." [18]! Dr. Abraham Myerson, chair of neurology at Tufts (19211940) was an exception and vehemently battled against eugenics.

Fairness also should indicate that Papez was not a mean spirited person. Mettler writes of Papez that "This excellence had three roots, the deepest of which was his sincerity, the most sustaining of which was his gentleness and the third was, curiously enough a certain vagueness. Dissatisfaction with mankind was difficult to arouse in Papez and when it did become manifest was highly unsophisticated." [19] "Being totally devoid of vanity or guile his only reaction to stupidity or avarice was a momentary, surprised unhappiness." Other terms include "... deep sincerity and abiding gentleness." Furthermore, "He may have become angry in his life but if he did I neither witnessed nor never heard about it and I know of no one to whom he ever spoke a harsh word or for whom he failed to do whatever was in his power." Paul Yakovlev reminisces about how pleasant Papez's visit to his laboratory and his home were. Papez charmed Yakovlev's children with animal stories [20].

A current burgeoning of neo-eugenics has been made possible by the ability to alter human genome lines. The two lead articles in the Nov. 16, 2017, New England 
Journal of Medicine entitled "Compelling Reasons for Repairing Human Genomes" and "Designing Ethical Trials of Germline Editing" reflect the reappearance of this new mode of eugenics [21, 22]. Those defending these techniques argue that decisions in neo-eugenics will be made by individuals not government. Even fixing or eliminating serious genetic disorders can become complicated. Since the availability of a cheap easy way of accurately diagnosing in utero Down's syndrome, some countries have launched programs to eliminate trisomy 21. In Iceland and Sweden, there has been a significant drop in the number of births of babies with
Down's syndrome. Recently, a countermovement has been decrying these programs arguing that it is not fair to eliminate a population based on a gene. They point out that Down's kids are very warm happy and loving [23]. Real trouble really looms when the genetic modifications might allow potential parents to engineer a baby selecting form a menu of what you think are valuable traits.

A final irony-Papez circuit and associated structures may be the reason why what appear to be "great ideas" like eugenics and communism fail when carried out by our limbically burdened species.
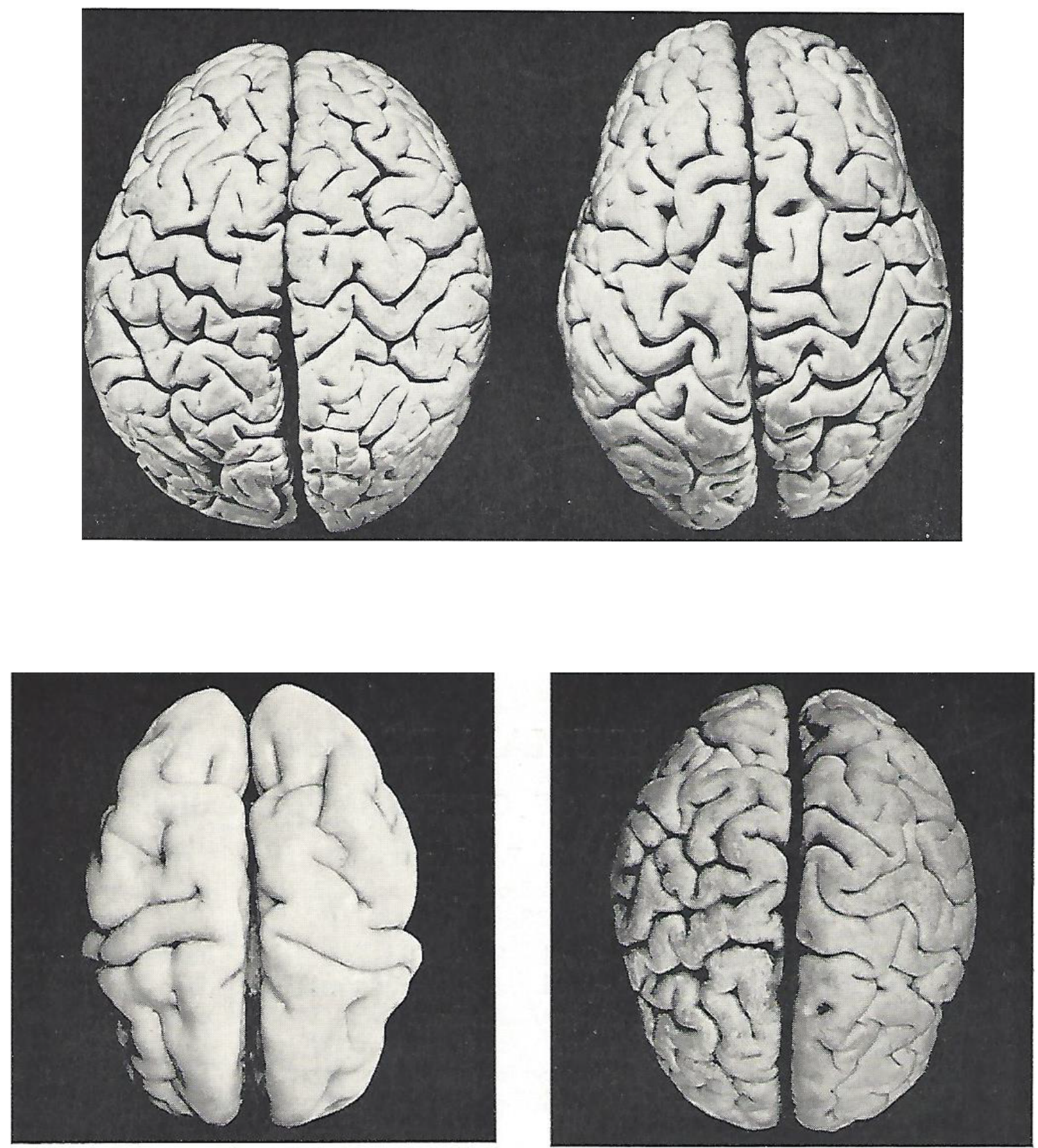

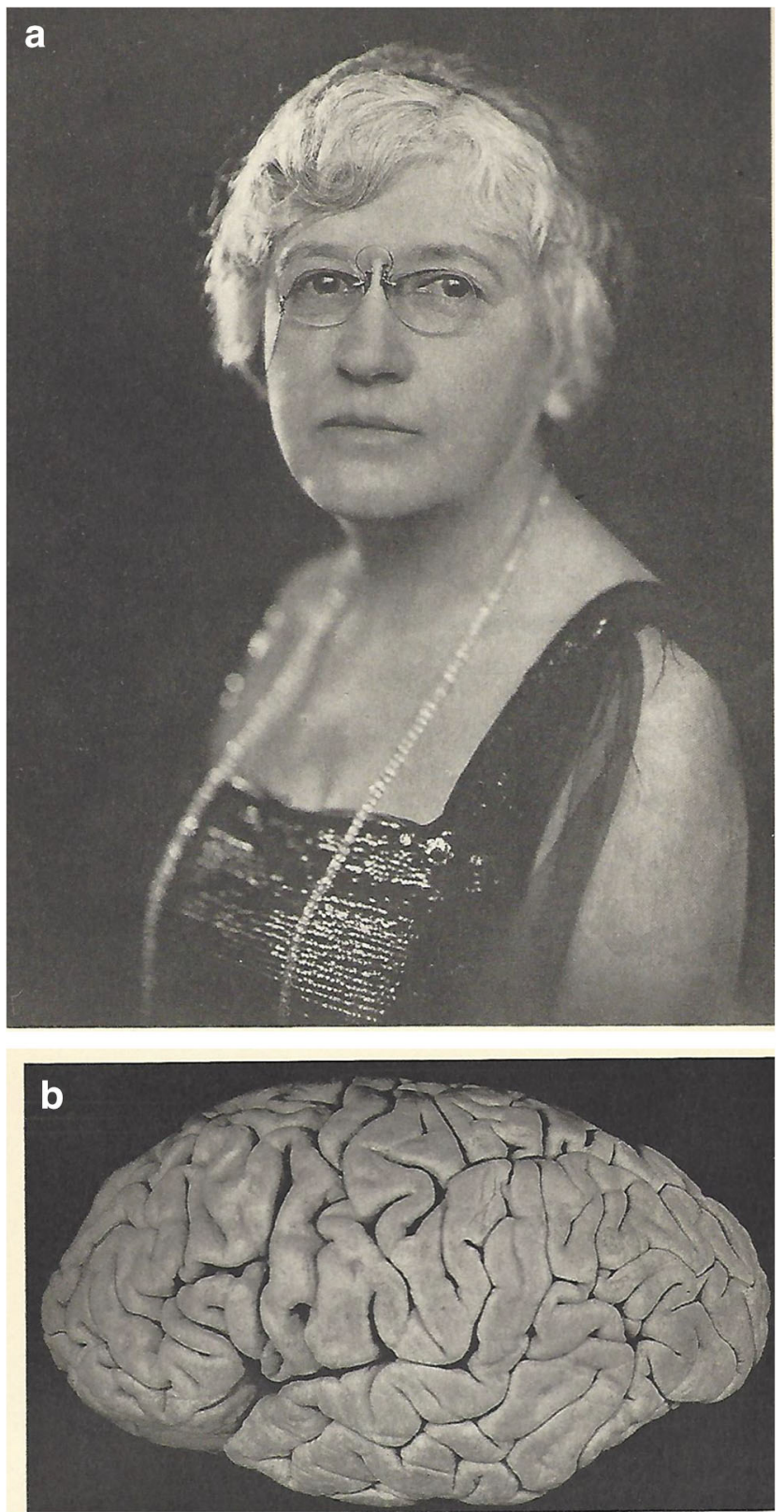

\section{Compliance with ethical standards}

Conflict of interest The author declares that there are no conflicts of interest.

No research committee approval is required because this paper is a historical vignette and no animals or human subjects were involved in its preparation.

Open Access This article is distributed under the terms of the Creative Commons Attribution 4.0 International License (http:// creativecommons.org/licenses/by/4.0/), which permits unrestricted use, distribution, and reproduction in any medium, provided you give appropriate credit to the original author(s) and the source, provide a link to the Creative Commons license, and indicate if changes were made.

\section{References}

1. Papez JW (1937) A proposed mechanism of emotion. Arch Neurol Psychiatr 38:725-743

2. Papez JW (1936) Subdivision of the facial nucleus. J Comp Neurol 43:159-191

3. Papez JW (1936) Evolution of the medial geniculate body nucleus. J Comp Neurol 64:41-61

4. Papez JW (1935) Thalamus of turtles and thalamic evolution. J Comp Neurol 61:433-475

5. Broca P (1878) Anatomie compare des circonvolutions cerebrales: Le grand lobe limbique et la scissure limbique dans la serie des mammiferres. Revue d" anthropologie 1: $365-498$ 
6. MacLean PD (1952) Some psychiatric implications of physiological studies on the frontotemporal portion of the limbic system (visceral brain). Electroencephalogr Clin Neurophysiol 4:407-418

7. Papez JW. Papez PS (1927) Comparative Neurology T.Y. Crrowell, New York

8. Papez JW. The human brain. Eugenics 1930-1932 III and IV

9. Papez JW (1930) The brain of Sutherland Simpson. J Comp Neurol 51(1):165-196

10. Papez JW (1927) The brain of Helen H Gardner (Alice Chenoworth day). Am J Phys Anthropol 11:29-88

11. Papez JW (1929) The brain of Burt Green Wilder. (1841-1925). J Comp Neurol 47(3):285-341

12. Vein AA, Maat-Schieman ML (2008) Famous Russian brains: historical attempts to understannd intelligence. Brain 131:583-590

13. Donaldson HH, Canavan MM (1928) The study of the brains of scholars: Granville Stanley Hall, Sir William Osler and Edward Sylvester Morse. J Comp Neurol:46

14. Falk D, Lepore Fe, Noe A (2013)The cerebral cortex of Albert Einstein: a description and preliminary analysis of unpublished photographs. Brain 136:1303-1327

15. Gregory MD, Kippenhan JS, Dickinson D et al (2016) Regional Variations in brain gyrification are associated with general cognitive ability in Humans. Sciencee Direct 23:1301-1305
16. Offen ML (2003) Dealing with "defectives": Foster Kennedy and William Lennox on eugenics. Neurology 61:668-673

17. Gittelman S (2017) When bigotry was science. Tufts Magazine Fall :46-49

18. Cohen A. Harvard's eugenics era. Harvard Magazine 2016 MarchApril

19. Mettler FA, James Wenceslas Papez. August 18, 1883-April 13, 1958 (1958) Anat Rec 131:279-282

20. Yakovlev PI (1978) Recollections of James Papez and comments on the evolution of the limbic system concept. In: Livingston KE, Hornykiewicz O (eds) Limbic mechanisms. Springer, Boston, pp Map352-Map353

21. Church G (2017) Compelling reasons for repairing human germlines. N Engl J Med 377:1909-1911

22. Cwik B (2017) Designing ethical trials of germline editing. N Eng J Med 377:1911-1913

23. Wise J (2016) The end of Down's syndrome? BMJ:355:15344

Publisher's note Springer Nature remains neutral with regard to jurisdictional claims in published maps and institutional affiliations. 